\title{
25 Research Suare \\ Religion/Spirituality, Moral Injury, and Mental Health among Health Professionals in China
}

\section{zhizhong wang ( $\nabla$ wzhzh_lion@126.com )}

Zunyi Medical University

\section{Faten Al Zaben}

Department of Medicine, King Abdulaziz University

\section{Harold.G. Koenig}

Duke University Medical Center

\section{Research Article}

Keywords: moral injury, depressive, health professional, mediation, COVID-19

Posted Date: September 17th, 2020

DOI: https://doi.org/10.21203/rs.3.rs-77800/v1

License: (1) This work is licensed under a Creative Commons Attribution 4.0 International License. Read Full License

Version of Record: A version of this preprint was published at BJPsych Open on September 17th, 2020. See the published version at https://doi.org/10.1192/bjo.2021.972. 


\section{Abstract}

Purpose: Moral injury (MI) is prevalent among healthcare professionals, and has been shown in those experiencing traumatic events to be associated with suicidal thoughts, depression, anxiety, and other adverse mental health outcomes. The present study examines the relationship between religion/ spiritual $(\mathrm{R} / \mathrm{S})$ and $\mathrm{Ml}$ among physicians and nurses in mainland China during the COVID-19 pandemic.

Methods: A cross-sectional study was conducted in 3,006 physicians and nurses in areas of China where the COVID-19 pandemic was causing high rates of hospitalization and death. The Moral Injury Symptoms Scale-Health Professional (MISS-HP) was administered along with measures of clinician mental health and R/S. Hierarchical linear regression modeling was used to examine the mediating and moderating effect of Ml on the relationship between R/S and mental health.

Results: Importance of religion was positively correlated with MI symptoms $(\beta=2.41, P<0.01)$, depressive $(\beta=0.74, P<0.01)$, and anxiety symptoms $(\beta=0.65, P<0.01)$ after controlling of multiple demographic variables. MI significantly mediated the relationship between $\mathrm{R} / \mathrm{S}$ and both depression and anxiety. MI explained $60 \%(0.46 / 0.76)$ of the total association between R/S and depression and $58 \%(0.38 / 0.65)$ of the association with anxiety. No moderating effect was found.

Conclusion: Although cross-sectional findings, these results suggest that concern over transgressing moral values during the pandemic may have been a driving factor for negative mental health symptoms among Chinese health professionals for whom religion was important. Future longitudinal studies are needed to determine the causal nature of these relationships.

\section{Introduction}

Moral injury (MI) among military personnel has gained considerable attention in mental health studies of military populations, where MI has been consistently linked with adverse outcomes such as suicide, depression, posttraumatic stress disorder (PTSD), and substance use disorders ${ }^{1,2,3}$. Litz et al. define MI as "perpetrating, failing to prevent, bearing witness to, or learning about acts that transgress deeply held moral beliefs." ${ }^{4} \mathrm{Ml}$ is thought to be a common syndrome characterized by symptoms such as shame, guilt, self-condemnation, feelings of betrayal, difficulty trusting, and difficulty forgiving ${ }^{10}$. Those who suffer from potentially morally injurious events (PMIEs), such as be physical or sexual abuse or other traumatic experiences, may have not only psychological injuries but also injuries to their spiritual health and well-being.

$\mathrm{Ml}$ is associated with religious / spiritual (R/S) suffering and a need to find hope, trust, connection, reconciliation, and wholeness ${ }^{6}$. Religious beliefs may provide coping resources (cognitive, social) and rituals (confession, repentance) for dealing with moral transgressions. Studies have found that religiosity is inversely associated with MI symptoms in U.S. Veterans ${ }^{7}$, and religious involvement may help to moderate the effects of MI on PTSD symptoms or promote recovery when such difficulties emerge ${ }^{8}$. 
Religious involvements may also increase the risk of $\mathrm{Ml}$ because some religious beliefs lower a person's threshold for morally injurious behaviors during combat and war ${ }^{9}$. Several interventions have been developed to address $\mathrm{MI}$ in the context of PTSD ${ }^{10}$, including a spiritually integrated version of cognitive processing therapy and other spiritual interventions that target $\mathrm{Ml}$ among veterans and active-duty military with PTSD symptoms ${ }^{11}$.

MI may also occur among healthcare professionals, particularly when clinicians feel their ability to deliver care is compromised by the systems being implemented by hospitals, clinics, and medical practices (e.g., insurance, reimbursement, electronic health record). ${ }^{12,13}$ Similar to military personnel on combat missions, physicians can be exposed to PMIEs in which they face ethical dilemmas related to agonizing life-death decisions, they often being asked to play God in hospitals short of medical devices such as ventilators, personal protective equipment, and lifesaving medications during the COVID-19 pandemic. This causes a sense of helplessness, shame, and guilt when hundreds of patients are dying every day, and there is nothing that can be done to save them. ${ }^{14} \mathrm{MI}$ may also be a consequence of the violence in that physicians may feel as a result of perceived betrayed by the very community that they serve, due to a recent increase in patient-physician mistrust and violence against physicians ${ }^{15}$. Many physicians have been killed and injured during the past decade in China due to such violence ${ }^{16}$. There is at least one qualitative study suggesting that the term "moral injury" is useful for exploring the experience of medical students in emergency medicine ${ }^{17}$.

To our knowledge, no research has yet examined the relationship between R/S and moral injury among physicians and nurses in mainland China or any other regions in the world. The present study seeks to explore the association between $\mathrm{R} / \mathrm{S}, \mathrm{Ml}$, and mental health in a national physician/nurse sample of Chinese healthcare professionals using an online survey. We hypothesized that (1) R/S would be positively associated with MI symptoms, (2) R/S would be positively related to depression and anxiety in this secular sample, (3) MI would help to explain (mediate) the relationship between R/S and depression/anxiety.

\section{Methods}

\section{Participants and Procedure}

Complete details on enrollment of participants have been described elsewhere ${ }^{18}$. In brief, 4,003 healthcare professionals were recruited from mainland China using a snowball sampling technique. An online survey was conducted between March 27 and April 26, 2020, about one month after the COVID-19 pandemic peak in China. A total of 3,975 participants agreed to complete the survey. Of those, 968 questionnaires were excluded during the data cleaning process for several reasons, including being in practice for less than two years, having two or more items with missing value on study measures, or giving the same or similar answer across all items (indicating lack of thoughtfulness when answering the questions). As a result, 3,006 participants were included in the final analysis. 
Inclusion criteria were 1) being a physician or nurse, and 2) length of time in practice at least two years. Exclusion criteria were (1) history of six months or more of an extended break from practice for any reason during the past two years; (2) inability to use the internet or other mobile device due to vision or other disability preventing the completion of an online questionnaire; and (3) not formally licensed to practice medicine or nursing in China. The survey was designed as anonymous, and online consent was obtained from all participants before proceeding. The study approved by the institutional review board of Ningxia Medical University (approval \#2020-112).

\section{Measures}

Information on sociodemographic characteristics was collected, including age, gender, marital status, educational attainment, ethnicity (Chinese Han, or minorities), area of specialty, work area, and length in practice.

MI was assessed using the 10-item Moral Injury Symptoms Scale-Health Professional (MISS-HP) developed by Mantri and colleagues (2020) ${ }^{19}$. This measure assesses ten dimensions of MI: betrayal, guilt, shame, moral concerns, loss of trust, loss of meaning, difficulty forgiving, self-condemnation, faith struggle, and loss of faith. Response options for each of the ten items ranges from 1 to 10 indicating agreement or disagreement, resulting in a total score from 10 to 100, with higher scores indicating greater $\mathrm{MI}^{20}$. The MISS-HP was translated into Chinese followed a standard procedure ${ }^{21}$. The Cronbach's alpha in the present sample was 0.71 in nurses and 0.70 in physicians.

The assessment of mental health included measures of depressive and anxiety symptoms using the 9item Patient Health Questionnaire (PHQ-9) and 7-item Generalized Anxiety Disorder (GAD-7), respectively. Both PHQ-9 and GAD-7 are rated on a 4-point Likert scale from 0 (not at all) to 3 (nearly every day) ${ }^{22,23}$. Higher scores indicate more severe depressive and anxiety symptoms. Chinese versions of the PHQ-9 and GAD-7 have been shown to have solid internal and test-retest reliability as well as construct and factor analytic validity in medical patients and the general population ${ }^{24,25}$. Cronbach's alphas for the present sample were 0.91 for the PHQ-9 and 0.94 for the GAD-7.

Religiosity/spirituality (R/S) was assessed by a single question asking about the importance of religion. This question is a commonly used to assess religiosity in secular societies and has been strongly associated with psychological well-being in many studies ${ }^{26}$. In the present study, importance of religion was measured using a Visual Analogue Scale (VAS) scale from 0 (not at all important) to 100 (very important) after asking the question: "In general, how important religious or spiritual beliefs in your daily life are?" Religious affiliation was also determined by asking the question: "What is your religion?" Religious affiliation was categorized for analysis into four groups: 1 = none, 2 = Chinese religion (i.e., Buddhist, Daoist, etc.), 3=Western religion (i.e., Christian), and 4=Muslim. 


\section{Statistical Analyses}

Descriptive statistics were used to determine average scores with standard deviations (SD) and ranges for continuous variables and numbers and percentages for categorical variables. Bivariate analyses were conducted using Pearson's $r$ for continuous variables and Student's t-test or ANOVA for comparing continuous variable scores across categorical variable responses.

Hierarchical linear regression modeling was used to examine the moderating effect of $\mathrm{MI}$ on the relationship between $\mathrm{R} / \mathrm{S}$ and mental health variables (depression and anxiety), controlling for demographic variables. First, associations between R/S and mental health (depression and anxiety separately) were determined after controlling for demographic variables (Model 1); this was followed by adding $\mathrm{Ml}$ to the model (Model 2). Finally, an interaction term between moral injury and R/S was added to model 2 (Model 3) to determine if MI moderated the relationship between R/S and mental health states.

Bootstrap methods of the PROCESS procedure in SPSS designed by Hayes ${ }^{27}$ were employed to examine the mediating effect of moral injury in the relationship between R/S and mental health depression/anxiety. The IBM SPSS 23.0 version was used to perform all analyses. Alpha level was set at 0.05 for statistical significance and was not adjusted for multiple comparisons due to the exploratory nature of these analyses.

\section{Results}

As indicated in Table 1, the final sample consisted of 583 nurses and 2,423 physicians. Participants were $65 \%$ female; nearly two-thirds (62.5\%) primarily provided inpatient care; $12.3 \%$ were minorities; and most held a bachelor's degree in their field (in China, a bachelor's degree is sufficient to practice medicine). The average age of participants was 35.4 years $(S D=8.1)$, ranging from age 20 to 70 years. The average length of practice was 11.6 years (range from 2 to 50 years). Most participants (89.2\%) indicated no religious affiliation; among those having a religion, Islam was the most common religious affiliation. Importance of religion scores ranged from 0 to 100 , with an average of $38.5(S D=28.5)$ and a median score of 40 . Christians reported the highest score on importance $(72, S D=27)$, Buddhist/Taoists reported similar scores as Muslims ( $58, S D=27, v s .59, S D=25$, respectively), and those who indicated no religion reported lowest scores $(35, \mathrm{SD}=27)$.

Bivariate analyses are presented in Table 1. Unmarried participants scored higher on the MISS-HP compared to the married, divorced or widowed $(p<0.01)$. Both older participants in those longer in practice scored lower on Ml symptoms. Both the depression (PHQ-9) and anxiety (GAD-7) symptoms were strongly and positively correlated with MISS-HP total scores $(p<0.01)$. Importance of religion score was positively correlated with MISS-HP scores. No significant difference was found between different religious affiliations or no affiliation. The associations between $\mathrm{R} / \mathrm{S}$ and $\mathrm{Ml}$ persisted in the multivariate analyses after controlling of the demographic variables. 
As indicated in Table 2, no significant difference on PHQ or GAD scores was found between groups based on religious affiliation. Multivariate analyses revealed that $R / S$ (importance of religion) was positively correlated with depressive symptoms $(\beta=0.74, \mathrm{P}<0.01)$ and with anxiety symptoms $(\beta=0.65, \mathrm{P}<0.01)$. The results of mediation model are presented in Table 3, after controlling for age, gender, education, marital status, and work area. The mediation effect (indirect effect) of MI on the relationship between R/S and depression/anxiety was significant $(p<0.001)$. Ml explained $60 \%(0.46 / 0.76)$ of the total association between R/S and depression and $58 \%(0.38 / 0.65)$ of the association between R/S and anxiety. As demonstrated in Table 4, there no significant moderating effect of $\mathrm{Ml}$ on the positive relationship between $\mathrm{R} / \mathrm{S}$ and either depression or anxiety symptoms (interaction for depression, $\beta=-0.01, \mathrm{p}=0.55$; interaction for anxiety, $\beta=-0.01, P=0.26$ ) (Model 3).

\section{Discussion}

To our knowledge, this is the first study to explore the relationship between importance of religion (R/S), moral injury (MI), and mental health (depression/anxiety) in a large sample of healthcare professionals during the COVID-19 pandemic in mainland China. We found that R/S was positively associated with $\mathrm{MI}$ symptoms, as well as with depressive and anxiety symptoms. These findings are not consistent with previous reports indicating that religiosity was inversely associated with MI in US veterans, a highly religious population. These conflicting results may be due to the measure of $\mathrm{Ml}$ in this study that assesses not only psychological symptoms but also struggles with religion, which may be more common among those with a religious faith, especially in a highly secular country. ${ }^{20}$ Several studies conducted in mainland China have reported a positive relationship between R/S and mental health problems (since religious Chinese are a minority and under unusual social stress) ${ }^{28}$. Chinese health professionals who are religious may feel abandoned or punished by God when experiencing difficult life situations, resulting in a higher level of moral distress. ${ }^{29}$ At least one study has reported that religious and moral issues among minority Muslims in Germany generated stress among women leading to a higher level of mental distress $^{30}$. More religious HCPs may be driven by higher values and morals that make them feel greater responsibility to "do something" to help others. When faced with system problems that prevent this, they feel helpless and therefore develop anxiety and depression.

Multivariate analyses found that MI was associated with both depression and anxiety symptoms with more Ml symptoms among Chinese health professionals in the current study. MI has been consistently linked with adverse mental health outcomes such as suicide, depression, PTSD, and substance misuse in military populations ${ }^{31,32}$. Although the present study utilizes a cross-sectional design, preventing causal inferences, spiritual-based interventions directed MI have been effective in reducing PTSD and other negative emotions among military personnel ${ }^{11}$.

Likewise, Mantri and colleagues found in a sample of healthcare professionals that MI was associated with depression and anxiety as in the present study ${ }^{33}$. 
We employed two models to explain how MI might be related to the relationship between R/S and depression/anxiety, through mediation and through moderation. The mediation model indicated that MI explained most of the variance in the relationship between R/S and both depression and anxiety. This suggests that Chinese health professionals who are more religious may be more sensitive emotionally to moral concerns over transgressing moral boundaries while carrying out their duties during the COVID-19 pandemic, where decisions might have often influenced who received treatment and who did not given limited resources. While R/S may increase level of hope in U.S. Veterans and active duty military, ${ }^{34}$ this dynamic may be difficult to demonstrate in a largely secular population of Chinese healthcare professionals, where other pressures on religious beliefs may be neutralizing of these benefits. We also did not find that MI symptom severity moderated the relationship between R/S and depression/anxiety, indicating that the relationship between R/S and depression/anxiety was positive regardless of level of moral injury symptoms.

The findings here provide primary evidence suggesting that integrating R/S into interventions for the treatment of $\mathrm{Ml}$ and depression/anxiety in religious Chinese healthcare professionals. ${ }^{11}$ Doing so will help to maintain the mental health and well-being of these frontline providers during the COVID-19 pandemic as well as other major public health events associated with potentially morally challenging decisions that Chinese healthcare professionals are likely to face in the future.

\section{Study Limitations}

Several limitations affect the interpretation and generalizability of the findings reported here. First, the nonrandom sampling method used here to select participants may affect the external validity of the results in terms of generalizing to HCPs across China. Second, the cross-sectional design prevents making causal inferences regarding the relationships between R/S, moral injury, and depression/anxiety. Finally, since all measures were self-rated, the accuracy of responses cannot be guaranteed in secular China, where religion may not be popular and may even be discouraged (despite the anonymous online survey design employed here).

\section{Conclusions}

While no difference was found between Ml symptom scores across religious affiliations and no affiliation, importance of religion was positively correlated with MI symptoms and poor mental health in this sample of Chinese healthcare professionals during the COVID-19 pandemic. MI mediated a significant proportion of the association between R/S and both depression and anxiety, suggesting that concern over transgressing moral values during the pandemic may have been a driving factor for negative mental health symptoms among religious Chinese health professionals. Although future longitudinal studies are needed to determine the causal nature of these relationships, these findings provide preliminary evidence justifying the integration of R/S into interventions directed at treating mental health issues that arise among religious Chinese health professionals during the COVID-19 pandemic. 


\section{Declarations}

Funding The China Medical Board partly support this study (16-254).

Competing Interest All authors declare no competing interests.

Ethics Statement The survey was designed as anonymous, and online consent obtained from all participants before the questionnaire proceeding. The study approved by the institutional review board of Ningxia Medical University (approval \#2020-112).

Consent for publication Not apply

Authors' Contribution Study concept and design: Wang ZZ, Koenig HG; acquisition of subjects and data collection: Wang ZZ, Liu HY; analysis and interpretation of data: Wang ZZ, Al Zaben F, Koenig HG; preparation of the manuscript: Wang ZZ; revision of the manuscript for critical intellectual content: Wang ZZ, Liu HY, Al Zaben F, Koenig HG.

Availability of data and material All data generated or analysed during this study are included in this published article. Additional request are available from the corresponding author.

\section{Acknowledgments}

We would like to show our acknowledgments to Dr. ZT Xue for her assistance in preparing the questionnaire, and to Drs. M Sui, J Wen, HY Liu and Y Tong for help in data collection. This study partly supported by the China Medical Board (16-254).

\section{References}

1. Bryan A O, Bryan CJ, Morrow C E, Etienne N, Ray-Sannerud B. Moral injury, suicidal ideation, and suicide attempts in a military sample. Traumatology 2014, 20(3):154-64.

2. Battles AR, Bravo A J, Kelley M L, Whit TD, Braitman A L, Hamrick HC. Moral injury and PTSD as mediators of the associations between morally injurious experiences and mental health and substance use. Traumatology 2018; 24(4): 246-54.

3. Ames, D., Erickson, Z., Youssef, N. A., Arnold, I., Adamson, C. S., Sones, A. C., ... \& Oliver, J. P. (2019). Moral injury, religiosity, and suicide risk in US veterans and active duty military with PTSD symptoms. Military medicine, 184(3-4), e271-e278.

4. Litz BT, Stein N, Delaney E, et al. Moral injury and moral repair in war veterans: a preliminary model and intervention strategy. Clin Psychol Rev. 2009; 29:695-706. 
5. Koenig HG, Ames D, Nash, W Büssing A. Screening for and treatment of moral injury in veterans/active duty military with PTSD. Frontiers in Psychiatry 2019; 10: 596.

6. Smith-MacDonald, L. A., Morin, J. S., \& Brémault-Phillips, S. (2018). Spiritual dimensions of moral injury: contributions of mental health chaplains in the Canadian armed forces. Frontiers in psychiatry, 9, 592.

7. Koenig, H. G., Youssef, N. A., Ames, D., Oliver, J. P., Teng, E. J., Haynes, K., ... \& Pearce, M. (2018). Moral injury and religiosity in US veterans with posttraumatic stress disorder symptoms. Journal of Nervous and Mental Disease, 206(5), 325-331.

8. Youssef, N. A., Boswell, E., Fiedler, S., Jump, R., Lee, E., Yassa, M., ... \& O'Garo, K. (2018). Moral injury, posttraumatic stress disorder, and religious involvement among US veterans. Annals of Clinical Psychiatry 30(2), 113-121.

9. Worthington EL, Langberg D (2012) Religious considerations and self-forgiveness in treating complex trauma and moral injury in present and former soldiers. J Psychol Theol. 40:274-288.

10. Nieuwsma, JA, Walser, RD, Farnsworth, JK, Drescher, KD, Meador, KG, Nash, WP. Possibilities within acceptance and commitment therapy for approaching moral injury. Current Psychiatry Review 2015; 11:193-206.

11. Pearce M, Haynes K, Rivera NR, Koenig HG. Spiritually Integrated Cognitive Processing Therapy: A New Treatment for Post-traumatic Stress Disorder That Targets Moral Injury. Global Advances in Health \& Medicine, 2018,7:1-7.; see also Harris, J. I., Erbes, C. R., Engdahl, B. E., Thuras, P., MurraySwank, N., Grace, D., ... \& Malec, C. The effectiveness of a trauma focused spiritually integrated intervention for veterans exposed to trauma. Journal of Clinical Psychology, 2011; 67(4), 425-438; Harris, J. I., Usset, T., Voecks, C., Thuras, P., Currier, J., \& Erbes, C. (2018). Spiritually integrated care for PTSD: A randomized controlled trial of “Building Spiritual Strength”. Psychiatry Research 2018; 267:420-428

12. Ford EW. Stress, Burnout, and Moral Injury. Journal of Healthcare Management 2019; 64 (3):125-27.

13. Frezza E. Moral Injury: The Pandemic for Physicians. Texas Medicine 2019; Mar:4-7.

14. BBC news. Coronavirus: Why healthcare workers are at risk of moral injury. https://www.bbc.com/news/world-us-canada-52144859. accessed May 5 $5^{\text {th }}, 2020$.

15. Tucker JD, Cheng Y, Wong B, et al. Patient-physician mistrust and violence against physicians in Guangdong Province, China: a qualitative study. BMJ Open 2015; 5(10), e008221.

16. Pan $Y$, hong Yang $X$, He J P, et al. To be or not to be a doctor, that is the question: a review of serious incidents of violence against doctors in China from 2003-2013. Journal of Public Health 2015; 23(2): 111-16.

17. Murray E, Krahé C, Goodsman D. Are medical students in prehospital care at risk of moral injury? Emergency Medicine Journal 2018; 35(10), 590-94. 
18. Wang, ZZ, Koenig, HG, Tong, Y., Wen, J., Sui, M., Liu, H., Liu, G. Psychometric properties of the Moral Injury Symptoms Scale among Chinese health professionals during the COVID-19 pandemic, 2020 [Preprint]. Research Square, https://doi.org/10.21203/rs.3.rs-32815/v1

19. Mantri, S., Lawson, J. M., Wang, Z. Z., Koenig, H. G. Identifying moral injury in healthcare professionals: The Moral Injury Symptoms Scale-HP. Journal of Religion and Health, 2020.in press. doi:10.1007/s10943-020-01065-w

20. Koenig H G, Ames D, Youssef N A, et al. Screening for moral injury: the moral injury symptom scalemilitary version short form. Military Medicine 2018, 183(11-12):659-65.

21. Cha E S, Kim KH, Erlen J A. Translation of scales in cross-cultural research: issues and techniques. Journal of advanced nursing, 2007; 58(4): 386-395. doi: 10.1111/j.1365-2648.2007.04242.x

22. Kroenke K, Spitzer RL, Williams JB: The PHQ-9: validity of a brief depression severity measure. Journal of General Internal Medicine 2001; 16(9):606-13

23. Spitzer RL, Kroenke K, Williams JB, Lowe B: A brief measure for assessing generalized anxiety disorder: GAD-7. Archives of Internal Medicine 2006;166(10):1092-97

24. Zhang YL, Liang W, Chen ZM, et al. Validity and reliability of Patient Health Questionnaire-9 and Patient Health Questionnaire-2 to screen for depression among college students in China. AsiaPacific Psychiatry 2013;5(4): 268-275.

25. He XY, Li CB, Qian J, Cui HS, Wu WY. Reliability and validity of a generalized anxiety scale in general hospital outpatients. Shanghai Archives of Psychiatry 2010; 22(4):200-203

26. Payne, I. R., Bergin, A. E., Bielema, K. A., \& Jenkins, P. H. (1991). Review of religion and mental health: Prevention and the enhancement of psychosocial functioning. Prevention in Human Services, 9(2), 11-40.

27. Hayes, A., 2013. Introduction to mediation, moderation, and conditional process analysis. J Educ Meas. 51, 335-337. doi: 10.1111/jedm.12050.

28. Wang Z, Koenig HG, Zhang Y, Ma W, Huang Y (2015) Religious involvement and mental disorders in Mainland China. PLoS ONE 10(6): e0128800; see also McClintock, C. H., Lau, E., \& Miller, L.

Phenotypic dimensions of spirituality: implications for mental health in China, India, and the United States. Frontiers in Psychology 2016; 7, 1600 (1-16); Zhang J, Wieczorek WF, Conwell Y, Ming Tu, X. Psychological strains and youth suicide in rural China. Social Sciences \& Medicine 2011; 72(12): 2003-2010

29. Braam AW, Schrier AC, Tuinebreijer WC, Beekman ATF, Dekker JJM, et al. (2010) Religious coping and depression in multicultural Amsterdam: A comparison between native Dutch citizens and Turkish, Moroccan and Surinamese/ Antillean migrants. J Affect Disord 125: 269-278. doi:

10.1016/j.jad.2010.02.116

30. Irfaeya M, Maxwell AE, Krämer A (2008) Assessing Psychological Stress among Arab Migrant Women in the City of Cologne/Germany Using the Community Oriented Primary Care (COPC) 
Approach. J Immigr Minor Health 10: 337-344.

31. Battles AR, Bravo AJ, Kelley ML, Whit TD, Braitman AL, Hamrick HC (2018). Moral injury and PTSD as mediators of the associations between morally injurious experiences and mental health and substance use. Traumatology 24, 246-254. doi: 10.1037/trm0000153.

32. Bryan AO, Bryan CJ, Morrow CE, Etienne N, Ray-Sannerud B (2014) Moral injury, suicidal ideation, and suicide attempts in a military sample. Traumatology 20:154-164. doi: 10.1037/h0099852.

33. Mantri, S., Lawson, J.M., Wang, Z.Z., Koenig, H.G. Prevalence and predictors of moral injury in healthcare professionals. Journal of Nervous and Mental Disease, 2020, in press

34. Koenig, H. G., Youssef, N. A., Smothers, Z., Oliver, J. P., Boucher, N. A., Ames, D., Volk, F., Teng, E. J., \& Haynes, K. (2020). Hope, Religiosity, and Mental Health in U.S. Veterans and Active Duty Military with PTSD Symptoms. Military Medicine, 185(12), 97-104. doi:10.1093/milmed/usz146

\section{Tables}


Table 1. Characteristics of the sample and bivariate correlates with MI in health professionals $\llbracket \mathrm{n}=3,006 \square$

\begin{tabular}{|c|c|c|c|c|}
\hline Variable & $\mathrm{N}(\%)$ & $\operatorname{Mean}(S D)$ & $\begin{array}{l}\text { MISS-HP } \\
\text { Mean }(S D)\end{array}$ & $B(95 \% C I)^{\mathrm{b}}$ \\
\hline \multicolumn{5}{|l|}{ Gender } \\
\hline Female & $1957(65.1)$ & & 46.7 (12.4) & $0.72(-0.27,1.72)$ \\
\hline Male & 1049 (34.9) & & $47.4(13.2)$ & \\
\hline \multicolumn{5}{|l|}{ Marital status } \\
\hline unmarried & $656(21.8)$ & & $48.4(12.1)^{* *}$ & $-0.67(-1.80,0.46)$ \\
\hline married & 2266 (75.4) & & $46.5(12.8)$ & \\
\hline divorced/widow & $84(2.8)$ & & $(46.3(12.3)$ & \\
\hline \multicolumn{5}{|l|}{ Ethnicity, } \\
\hline Han & 2637 (87.7) & & $46.9(12.7)$ & $-0.10(-1.48,1.27)$ \\
\hline minorities & $371(12.3)$ & & $46.9(12.1)$ & \\
\hline \multicolumn{5}{|l|}{ nurse/ physicians } \\
\hline nurse & $583(19.4)$ & & $46.2(12.2)$ & $0.91(-0.37,2.18)$ \\
\hline physicians & $2423(80.6)$ & & $47.1(12.8)$ & \\
\hline \multicolumn{5}{|l|}{ Work area } \\
\hline inpatient & $1878(62.5)$ & & $46.9(12.8)$ & $-0.21(-0.75,0.32)$ \\
\hline outpatient & 714 (23.8) & & $47.0(12.6)$ & \\
\hline ICU/emergency & $280(9.3)$ & & $46.8(12.6)$ & \\
\hline Other & $134(4.5)$ & & $48.1(10.8)$ & \\
\hline \multicolumn{5}{|l|}{ Education } \\
\hline Bachelor & 2029 (67.5) & & $47.1(12.5)$ & $0.44(-0.33,1.22)$ \\
\hline Master & $813(27.0)$ & & $46.8(13.0)$ & \\
\hline Ph.D. & $164(5.5)$ & & $45.8(13.2)$ & \\
\hline Age (range $=20-70$ ), years & & $35.4(8.1)$ & $-0.082^{* *}$ & $-0.12(-0.19,-0.06)^{* *}$ \\
\hline LOP (range $=2-50$ ), years & & 11.6(8.5) & $-0.085^{* *}$ & $-0.11(-0.17,-0.05)^{* *}$ \\
\hline \multicolumn{5}{|l|}{ Religion affiliation } \\
\hline No & 2680 (89.2) & & $46.8(12.7)$ & $0.42(0.25,-0.30)$ \\
\hline Christian/Catholic & $29(1.0)$ & & $47.7(11.2)$ & \\
\hline Buddhist/Taoist & $103(3.4)$ & & 48.6(13.5) & \\
\hline Islam & $194(6.5)$ & & $47.5(11.7)$ & \\
\hline Depression (range $=0-30$ ) & & $10.6(6.0)$ & $0.437^{* *}$ & $0.91(0.84,0.99)^{* *}$ \\
\hline Anxiety (range=0-24) & & $8.3(5.3)$ & $0.406^{* *}$ & $0.96(0.88,1.04)^{* *}$ \\
\hline IR (range $=0-100$ ) & & $38.5(28.5)$ & $0.074^{* *}$ & $2.41(1.65 .3 .18)^{* *}$ \\
\hline
\end{tabular}

MISS-HP: Moral injury symptom scale- health professional; PHQ: Patient Health Questionnaire; GAD: Generalized Anxiety Disorder; LOP $\square$ length of practice $\square$ IR $\square$ Importance of religion.

a: Pearson correlation (r) was used to determine the association between MISS-HP and continuous variables; Student's t-test or analysis of variance was used to compare the average MISS-HP scores across categorical variables; b: General linear model used to control the covariates $* * \mathrm{p} \leq 0.01$ 
Table 2. Correlations of R/S and mental health conditions in healthcare professionals $\square \mathrm{n}=3,006 \square$

\begin{tabular}{|c|c|c|c|c|}
\hline \multirow[t]{2}{*}{ Variable } & \multicolumn{2}{|c|}{ Depression (PHQ) } & \multicolumn{2}{|c|}{ Anxiety (GAD) } \\
\hline & $\operatorname{Mean}(S D) / \mathrm{r}^{\mathrm{a}}$ & $B(95 \% C I)^{\mathrm{b}}$ & $\operatorname{Mean}(S D) / \mathrm{r}^{\mathrm{a}}$ & $B(95 \% C I)^{\mathrm{b}}$ \\
\hline \multicolumn{5}{|l|}{ Religious affiliation } \\
\hline No & $10.5(6.0)$ & $0.21(-0.12,0.55)$ & $8.2(5.3)$ & $0.08(-0.21,0.38)$ \\
\hline Christian & $11.9(5.4)$ & & $8.8(5.5)$ & \\
\hline Buddhist/Taoist & $10.9(6.6)$ & & $8.6(5.7)$ & \\
\hline Islam & $11.5(5.6)$ & & $8.7(4.6)$ & \\
\hline $\mathrm{IR}^{\#}$ (range $\left.=0-100\right)$ & $0.043^{*}$ & $0.74(0.24,1.24)^{* *}$ & 0.034 & $0.65(0.21,1.09)^{* *}$ \\
\hline
\end{tabular}

PHQ: Patient Health Questionnaire; GAD: Generalized Anxiety Disorder; IR $\square$ Importance of religion.

a: Pearson correlation (r) was used to determine the association between IR and continuous variables; Student's t-test or analysis of variance was used to compare the average PHQ score and GAD score across religious affiliation groups; b: General linear model used to control the covariates ((gender, marital status, ethnicity, work area, education, length of practice);

\# the score in logarithm transform to meet normal distribution;

${ }^{*} \mathrm{P}<0.05 ; * * \mathrm{p}<0.01$;

Table 3. Model examining the mediating effect of moral injury on the relationship between importance of religion and depression and anxiety

\begin{tabular}{|c|c|c|c|c|c|}
\hline \multirow[t]{2}{*}{ Effect } & \multirow[t]{2}{*}{$\beta$} & \multirow[t]{2}{*}{$S E$} & \multirow[t]{2}{*}{$P$ value } & \multicolumn{2}{|c|}{ Bias-Corrected $95 \% C I$} \\
\hline & & & & Lower & Upper \\
\hline \multicolumn{6}{|l|}{ Depressive symptoms } \\
\hline Total effect & 0.76 & 0.18 & $<0.001$ & 0.42 & 1.11 \\
\hline Indirect Effects & 0.46 & 0.08 & $<0.001$ & 0.30 & 0.63 \\
\hline Direct Effects & 0.30 & 0.16 & 0.064 & -0.02 & 0.62 \\
\hline \multicolumn{6}{|l|}{ Anxiety symptoms } \\
\hline Total effect & 0.65 & 0.16 & $<0.001$ & 0.34 & 0.95 \\
\hline Indirect Effects & 0.38 & 0.07 & $<0.001$ & 0.24 & 0.52 \\
\hline Direct Effects & 0.27 & 0.14 & 0.067 & -0.02 & 0.55 \\
\hline
\end{tabular}


Table 4. Moderating effect of MI on the relationship between R/S and depression and anxiety

\begin{tabular}{|c|c|c|c|c|c|c|}
\hline \multirow[t]{2}{*}{ Variables } & \multicolumn{2}{|r|}{ Model 1} & \multicolumn{3}{|c|}{ Model 2} & Model 3 \\
\hline & $p$ value & $B(95 \% C I)$ & $p v$ & $B(95 \% C I)$ & & $B(95 \% C I)$ \\
\hline \multicolumn{7}{|c|}{ Depressive symptoms } \\
\hline Constant & $<0.001$ & $11.25(10.0,12.4)$ & 0.020 & $1.58(0.25,2.91)$ & 0.425 & $0.97(-1.42,3.37)$ \\
\hline $\mathrm{IR}^{\#}$ & 0.001 & $0.85(0.33,1.37)$ & 0.180 & $0.29(-0.13,0.73)$ & 0.337 & $0.73(-0.76,2.22)$ \\
\hline MISS-HP & -- & -- & $<0.001$ & $0.20(0.18,0.22)$ & $<0.001$ & $0.21(0.17,0.22)$ \\
\hline IR $\times$ MISS-HP & -- & -- & - & -- & 0.552 & $-0.01(-0.04,0.02)$ \\
\hline Model $\mathrm{R}^{2} / \Delta \mathrm{R}^{2}$ & -- & $0.010 /--$ & - & $0.193 / 0.184^{* *}$ & -- & $0.193 / 0.000$ \\
\hline \multicolumn{7}{|l|}{ Anxiety symptoms } \\
\hline Constant & $<0.001$ & $9.89(9.04,10.75)$ & 0.158 & $0.85(-0.33,2.05)$ & 0.877 & $-0.17(-2.32,1.98)$ \\
\hline $\mathrm{IR}^{\#}$ & 0.001 & $0.69(0.26,1.11)$ & 0.238 & $0.23(-0.15,0.62)$ & 0.075 & $0.97(-0.36,2.23)$ \\
\hline MMIS-HP & -- & -- & $<0.001$ & $0.16(0.15,0.18)$ & $<0.001$ & $0.19(0.14,0.23)$ \\
\hline IR $\times$ MISS-HP & -- & -- & - & -- & 0.259 & $-0.01(-0.04,-0.01)$ \\
\hline Model $\mathrm{R}^{2} / \Delta \mathrm{R}^{2}$ & -- & $0.010 /--$ & - & $0.167 / 0.166^{* *}$ & -- & $0.168 / 0.001$ \\
\hline
\end{tabular}

Model 1: Independent variables include demographical variables; Model2: Model 1+ MISS-HP; Model 3: model 2+ interaction;

IR: the importance of religion; MISS-HP: Moral injury symptom scale- health professional;

\# the score in logarithm transform to meet normal distribution;

* $\mathrm{R}$ square change test $\mathrm{p}<0.01$ 